\title{
Preparation and Reactivity of Poly [ $N$-(arylmethyl)phenazasiline]s. Effects of Substituent on the N Atom on Poly(phenazasiline)
}

\author{
Hidenobu NAKaO, ${ }^{\dagger \dagger}$ Hideki HaYASHI $,{ }^{\dagger},{ }^{\dagger \dagger}$ and Koichi OKITA ${ }^{*}$ \\ Advanced Materials Laboratory, Japan Chemical Innovation Institute, 2-1-6 Sengen, \\ Tsukuba, Ibaraki 305-0047, Japan \\ ${ }^{*}$ Research and Development Division, Japan Chemical Innovation Institute, 1-3-5 \\ Kanda-Jinbocho, Chiyoda-ku, Tokyo 101-0051, Japan
}

(Received December 28, 2000; Accepted March 13, 2001)

KEY WORDS Poly(phenazasiline)/ Reduction / Effect of the Substituent /

Phenazasiline, monosilane unit-fused diphenylamine derivatives, are potentially useful as hole transporting layer for electroluminescent (EL) devices, ${ }^{1 \mathrm{a}}$ antioxidants, ${ }^{1 \mathrm{~b}}$ additives for jet-engine lubricants, ${ }^{1 \mathrm{c}}$ and thermal stable polymers. ${ }^{2 a}$ Casalbore-Miceri and coworkers synthesized phenazasiline homopolymers by electrochemical oxidation of trimethylphenazasiline and examined electrochromic behaviors, ${ }^{2 b}$ but the structures of the polymers, and junctures of repeat units in particular were not clear. We reported the preparation of phenazasiline-containing $\pi$-conjugated polymers by reductive coupling of 2,8-dibromophenazasiline to obtain well-defined structures. ${ }^{3}$ The resulting polymers displayed interesting electochromism and high efficiency as hole transporting polymeric material. The substituent on the Si atom of reported poly(phenazasiline) did not change UV $\lambda_{\max }$ of the polymer, ${ }^{3}$ in spite of different dihedral angles between two benzene atoms from X-Ray analysis of related monomers. ${ }^{4}$ However, the reported phenazasiline-containing polymers had only methyl substituent on the $\mathrm{N}$ atom. ${ }^{2,3}$ This paper reports preparation of poly(phenazasiline) with arylmethyl and $\mathrm{H}$ substituent on the $\mathrm{N}$ atom, and the effects of the substituent.

\section{EXPERIMENTAL}

\section{Reagent}

$2,2^{\prime}, 4,4^{\prime}$-Tetrabromodiphenylamine was prepared by the reported method. ${ }^{5}$ Other chemicals were used as purchased.

\section{Measurement}

IR spectra were recorded on a JASCO FT-IR 610 spectrometer. NMR spectra in solution were taken using a Brucker ARX-300 spectrometer. UV-visible spectra were measured with a Shimadzu UV-3100 and Hitachi U3500 spectrometers, respectively.

Cyclicvoltammograms (CV) of the polymers were measured as follows. Electrochemical control of the experiments was achieved using a BAS electrochemical analyzer model 660. A three-electrode system was used, consisting of a Glassy Carbon (GC) electrode (BAS, $3 \mathrm{~nm}$ in diameter) or ITO electrode as the working electrode, a platinum wire counter electrode, and a $\mathrm{Ag} / \mathrm{Ag}^{+}$(10 mM $\mathrm{AgNO}_{3}$ ) reference electrode. Tetrabutylammonium perchlolate (TBAP) was used for electrolyte.

Preparation of Bis(2,4-dibromomethyl)-(2-naphtylmethyl)amine $\mathbf{1 b}$

Under nitrogen, 2,2',4,4'-tetrabromodiphenylamine (10.74 g, $22 \mathrm{mmol}$ ) was added to a dispersion of $\mathrm{NaH}$ $(60 \%$ in oil, $0.99 \mathrm{~g}, 24 \mathrm{mmol})$ in dry THF $\left(35 \mathrm{~cm}^{3}\right)$ and stirred for $1 \mathrm{~h}$ at $50^{\circ} \mathrm{C}$. (2-Bromomethyl)naphthalene $(4.91 \mathrm{~g}, 23 \mathrm{mmol})$ was added to the mixture and stirred for overnight at $60^{\circ} \mathrm{C}$. The reaction mixture was extracted by ether and purified by silica gel column chromatography (eluent=hexane) to give $(11.28 \mathrm{~g} 18.0$ $\mathrm{mmol})$ of $\mathbf{1 b}$. Yield was $83 \% .{ }^{1} \mathrm{H} \mathrm{NMR}\left(\mathrm{CDCl}_{3}\right) ; 6.8-8.1$ (m, 13) and $4.97 \mathrm{ppm}(\mathrm{s}, 2)$. Anal. Calcd for $\mathrm{C}_{23} \mathrm{H}_{15} \mathrm{Br}_{4} \mathrm{~N}$ : C, $44.2 \%$; H, 2.4\%; N, 2.2\%. Found: C, $44.0 \% ; \mathrm{H}, 2.6 \% ; \mathrm{N}$, $1.9 \%$.

Compound 1a was obtained similarly.

Preparation of 2,8-Dibromo-10,10-di-n-butyl-5-(2naphthylmethyl)phenazasiline (2b)

Under nitrogen, to a dispersion of $\mathbf{1 b}(1.29 \mathrm{~g}, 2.1$ $\mathrm{mmol})$ in dry ether $\left(20 \mathrm{~cm}^{3}\right)$ were added $1.6 \mathrm{M}$ hexane solution of $n$-butyllithium $\left(3 \mathrm{~cm}^{3}, 4.8 \mathrm{mmol}\right)$ at $0^{\circ} \mathrm{C}$. After the reaction mixture became homogeneous, di- $n$ butyldichlorosilane $(0.44 \mathrm{~g}, 0.21 \mathrm{mmol})$ was added at $0^{\circ} \mathrm{C}$ and stirred overnight at room temperature. The reaction mixture was purified by silica gel column chromatography (eluent $=$ hexane $)$ to give $0.51 \mathrm{~g}(0.84 \mathrm{mmol}, 40 \%)$ of 1b. Yield was $40 \% .{ }^{1} \mathrm{H} \mathrm{NMR}\left(\mathrm{CDCl}_{3}\right) ; 6.8-8.0(\mathrm{~m}, 13)$, $5.41(\mathrm{~s}, 2)$, and $1.0-2.0 \mathrm{ppm}(\mathrm{m}, 18) ;{ }^{13} \mathrm{C} \mathrm{NMR}\left(\mathrm{CDCl}_{3}\right)$; $148.81,135.77,134.40,133.45,132.99,132.63,128.90$, $127.70,126.40,125.93,124.76,123.92,122.64,118.21$, $113.69,56.65,26.38,25.78,13.76$, and $13.65 \mathrm{ppm} .{ }^{29} \mathrm{Si}$ NMR $\left(\mathrm{CDCl}_{3}\right) ;-21.18 \mathrm{ppm}$. Anal. Calcd for $\mathrm{C}_{31} \mathrm{H}_{33}$ $\mathrm{NSiBr}_{2}$ : C, $61.3 \% ; \mathrm{H}, 5.5 \%$;, $2.3 \%$. Found: C, $61.1 \% ; \mathrm{H}$, $5.4 \% ; \mathrm{N}, 2.1 \%$.

\footnotetext{
${ }^{\dagger}$ To whom correspondence should be addressed.

${ }^{\dagger+}$ Present address: National Agricultural Research Center, 3-1-1 Kannondai, Tsukuba, Ibaraki 305-8666, Japan.

${ }^{\dagger+}{ }^{+}$Present address: Nagoya Municipal Industrial Research Institute, 3-4-41 Rokuban, Atsuta-ku, Nagoya 456-0058, Japan.
} 
Other monomers $\mathbf{2 a}, \mathbf{2 c}$, and $\mathbf{2 d}$ were obtained similarly.

Preparation of Poly(10,10-di-n-butyl-5-(2-naphthylmethyl)phenazasiline-2,8-diyl) $\mathbf{3 b}$

Under nitrogen, to a mixture of $\mathrm{Ni}(\operatorname{cod})_{2}(0.28 \mathrm{~g}, 1.0$ mmol, $\operatorname{cod}=1,5$-cyclooctadiene), $\operatorname{cod}\left(1 \mathrm{~cm}^{3}\right)$ and $2,2^{\prime}$ bipyridyl $(0.16 \mathrm{~g}, 1.0 \mathrm{mmol})$ in toluene $\left(5 \mathrm{~cm}^{3}\right)$ was added phenazasiline $\mathbf{1 b}(0.42 \mathrm{~g}, 0.7 \mathrm{mmol})$ and the mixture was heated at $60^{\circ} \mathrm{C}$ for $48 \mathrm{~h}$. A white powder precipitated upon pouring the mixture into methanol was successively washed with $2 \mathrm{M}$ aqueous hydrochloric acid, methanol and hexane, and was dissolved in THF. Reprecipitation into methanol afforded $0.27 \mathrm{~g}(0.6 \mathrm{mmol}$ monomer unit, $87 \%$ ) of $\mathbf{3 b}$ as a white powder. ${ }^{1} \mathrm{H}$ NMR $\left(\mathrm{CDCl}_{3}\right) ; 6.8-8.0(\mathrm{~m}, 13 \mathrm{H}), 5.4(\mathrm{~s}, 2 \mathrm{H})$, and $1.0-2.0 \mathrm{ppm}$ $(\mathrm{m}, 18 \mathrm{H}) ;{ }^{13} \mathrm{C} \mathrm{NMR}\left(\mathrm{CDCl}_{3}\right) ; 149.15,135.60,133.61$, $132.65,132.32,131.82,128.76,126.29,125.77,124.91$, $120.47,116.47,56.79,26.55,26.09,14.20$, and 13.76 ppm. Anal. Calcd for $\left(\mathrm{C}_{31} \mathrm{H}_{33} \mathrm{NSi} \cdot \mathrm{H}_{2} \mathrm{O}\right)_{n}$ : C, $80.0 \%$; $\mathrm{H}$, $7.6 \%$;, $3.0 \%$. Found: C, 79.6\%; H, 7.3\%; N, $2.8 \%$.

The polymers $\mathbf{3 a}, \mathbf{3 c}$, and $\mathbf{3 d}$ were obtained similarly.

Chemical Preparation of Poly(10,10-di-n-butyl-
phenazasiline-2,8-diyl) $(\mathbf{4 b}$-c)
Under nitrogen, $34 \mathrm{mg}$ of $\mathbf{3 b}$ were added to $10 \mathrm{~cm}^{3}$ THF containing $0.8 \mathrm{~g}$ of sodium shot and the reaction mixture was stirred for overnight at room temperature. 2-Propanol was added to the reaction mixture to stop the reaction. Solvent was removed under vacuum. The residue was washed with methanol and dried under vacuum to obtain $23 \mathrm{mg}$ of 4b-c. Polymers $4 \mathbf{a}-\mathbf{c}$ and $\mathbf{4 c - c}$ were obtained similarly.

\section{RESULTS AND DISCUSSION}

Scheme 1 illustrates the preparation of 3. Dilithiation of compound 1 using $n$-BuLi in ether followed by addition of dichlorosilane produced monomer 2 . Polymers 3 were prepared through dehalogenative polycondensa$\operatorname{tion}^{3 \mathrm{a}, 6}$ of monomer 2. Data of polymer 3 are shown in Table I. Obtained polymers 3 were soluble in usual organic solvents like chloroform, 1,2-dichloroethane, and THF. UV $\lambda_{\text {max }}$ of the polymers 3 (see Table I) was almost the same region of that of reported $\operatorname{poly}(N$ methylphenazasiline) PPhenaz-Me ( $\lambda_{\max }=361$ and 366 $\mathrm{nm}$ with $\mathrm{R}=\mathrm{Me}$ and $n-\mathrm{C}_{8} \mathrm{H}_{17}$ substituent on the $\mathrm{Si}$ atom, respectively). ${ }^{3}$ This suggests that the aryl unit of the side chain of $\mathbf{3}$ has no effect on the $\pi$-conjugation system of poly(phenazasiline) main chain.

As shown in Figure 1a, CV of dichloromethane solution of $\mathbf{3}$ showed two reversible oxidation peaks seen in typical poly(arylamine) type polymer. As shown in Fig- ure $1 \mathrm{~b}, \mathrm{CV}$ of the $\mathbf{3 b}$ film showed two oxidation peaks, but the polymer film was dissolved in solution by electrochemical oxidation. The polymer film cast on an ITO glass plate was colorless when neutral, but the color changed to yellow, brown, and finally black with increase in the electrode potential to $+1.0 \mathrm{~V}$. When 3 was reduced to $-3.2 \mathrm{~V}$, CV showed reduction current which was not found in PPhenaz-Me. Interestingly, as shown in Figure 1c, CV curve of the product by electrochemical reduction of 3 (4-e) was different from that of 3 and oxidation potential became lower. Electrochromic behavior of 4-e was different from 3 . The color of the cast film was colorless when neutral, but the color changed to red, reddish purple, and finally purple with increase in electrode potential. This color change was almost the same as for poly(diphenylamine). ${ }^{6 \mathrm{~b}}$ To investigate change of the molecular structure, IR spectra of the polymers were measured. As shown in Figure 2, the IR spectrum of 4-e showed a $\delta(\mathrm{NH})$ peak at about $3400 \mathrm{~cm}^{-1}$ which could not be seen for 3. From CV and IR data, the structure of 4-e contained an $\mathrm{NH}$ unit, that is, poly(phenazasiline2,8-diyl) with an $\mathrm{NH}$ unit was formed by electrochemical reduction of $\mathbf{3}$ (eq 2 ). X (see eq 2 ) was estimated as 0.5

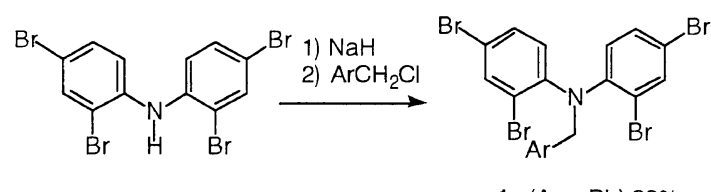

$1 \mathbf{a}(\mathrm{Ar}=\mathrm{Ph}) 83 \%$ 1 b $(\mathrm{Ar}=2$-nap) $82 \%$

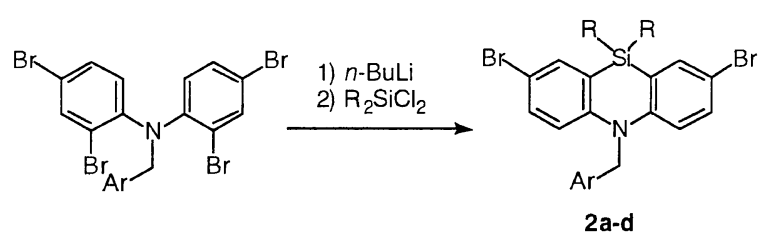

2a: $(\mathrm{R}=\mathrm{Me}, \mathrm{Ar}=2-\mathrm{nap}) 58 \%$ 2b: $(\mathrm{R}=n-\mathrm{Bu}, \mathrm{Ar}=2-\mathrm{nap}) 40 \%$ 2c: $(R=n$-oct, $\operatorname{Ar}=2$-nap) $91 \%$ 2d: $(\mathrm{R}=n$-oct, $\mathrm{Ar}=\mathrm{Ph}) 69 \%$

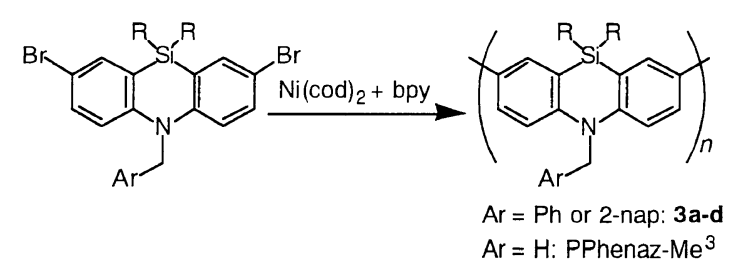

$\mathrm{Ni}(\operatorname{cod})_{2}=$ bis $(1,5-$ cyclooctadiene $)$ nickel $(0)$, bpy $=2,2^{\prime}-$ bipyridyl<smiles>Cc1ccc2ccccc2c1</smiles>

Scheme 1.

Table I. Results of preparation and spectral data of $\mathbf{3}$

\begin{tabular}{|c|c|c|c|c|c|c|c|}
\hline Polymer & $\mathrm{R}$ & $\mathrm{Ar}$ & Yield $/ \%$ & $M_{\mathrm{w}} / 10^{3 \mathrm{a}}$ & $\begin{array}{c}{ }^{13} \mathrm{C} \mathrm{NMR} \text { of } \\
\mathrm{N}-\mathrm{CH}_{2}-\mathrm{Ar} / \delta^{\mathrm{b}}\end{array}$ & ${ }^{29} \mathrm{Si} \mathrm{NMR} / \delta^{\mathrm{b}}$ & $\mathrm{UV} \lambda_{\max } / \mathrm{nm}$ \\
\hline $\mathbf{3 a}$ & $\mathrm{Me}$ & 2-nap & 86 & $0.8(3.0)$ & 56.47 & -23.24 & 362 \\
\hline $\mathbf{3 b}$ & $n-\mathrm{Bu}$ & 2-nap & 87 & $2.4(2.3)$ & 56.79 & -21.19 & 369 \\
\hline $3 \mathbf{c}$ & $n$-Oct & 2-nap & 95 & $2.1(2.6)$ & 56.83 & -21.34 & 365 \\
\hline $3 d$ & $n$-Oct & $\mathrm{Ph}$ & 69 & $2.0(2.4)$ & 52.42 & -21.23 & 369 \\
\hline
\end{tabular}

${ }^{\mathrm{a}} \mathrm{GPC}$ (THF, polystyrene standard). Figure in parenthesis is $M_{\mathrm{w}} / M_{\mathrm{n}} .{ }^{\mathrm{b}}$ In $\mathrm{CDCl}_{3} . \quad{ }^{\mathrm{c}} \mathrm{CHCl}_{3}$ solution. 


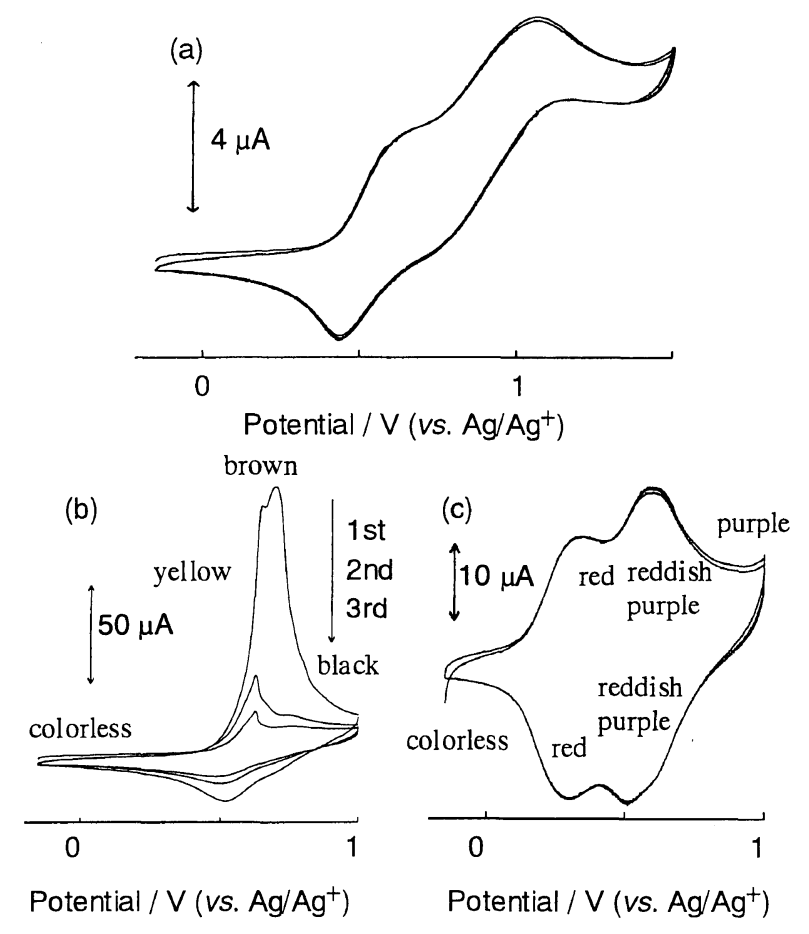

Figure 1. CV curves of the polymers. a) $\mathrm{CH}_{2} \mathrm{Cl}_{2}$ solution of $\mathbf{3 b}$ containing TBAP $(0.1 \mathrm{M})$ at $50 \mathrm{mV} \mathrm{s}^{-1}$. b) $3 \mathbf{b}$ and c) $4 \mathbf{b}-\mathbf{e}$ film. The polymer $\mathbf{3 b}$ was cast from 1,2-dichloroethane. In a $\mathrm{CH}_{3} \mathrm{CN}$ solution of TBAP $(0.1 \mathrm{M})$. At $50 \mathrm{mV} \mathrm{s}^{-1}$.

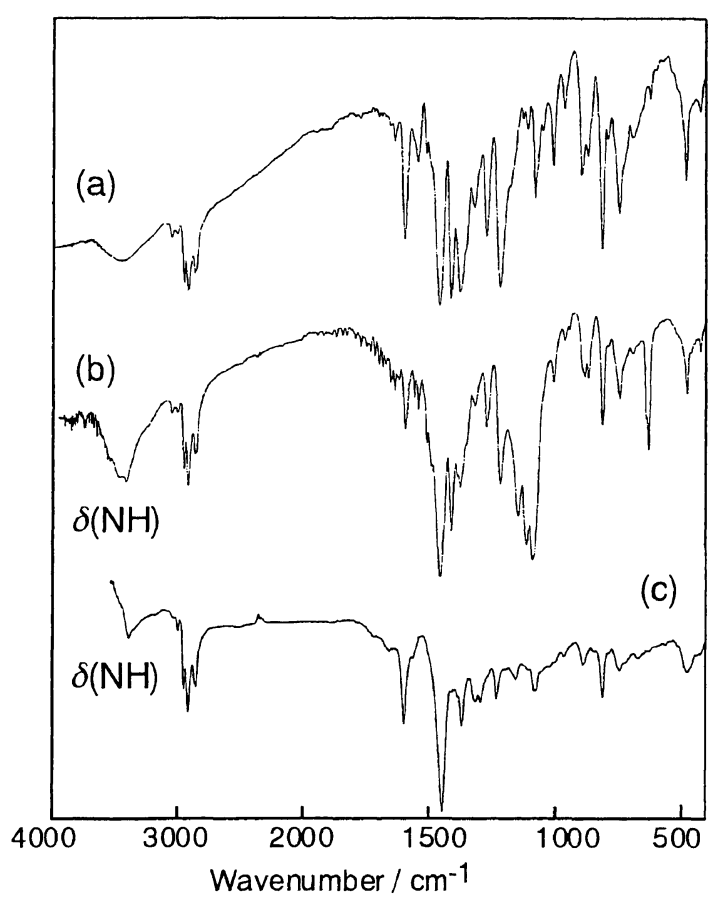

Figure 2. IR spectra of a) $3 b$, b) $4 b-e$, and c) $4 b-c$. from IR spectra and CV data. Figure 1c indicats that the $\mathrm{CV}$ curve shows only the redox of poly(phenazasiline) with the $\mathrm{NH}$ unit although $x$ was 0.5 , possibly because the unreacted arylmethylphenazasiline unit was dissolved in solution.

Since 4 was prepared by electrochemical reduction of $\mathbf{3}$, we tried to reduce $\mathbf{3}$ chemically. Chemical reduction of $\mathbf{3}$ by sodium afforded 4-c in high yield (Table II). X of 4-c was almost 1 from IR and NMR data. IR spectrum of 4-c showed an $\mathrm{NH}$ peak (Figure $2 \mathrm{c}$ ). ${ }^{1} \mathrm{H}$ and ${ }^{13} \mathrm{C}$ NMR spectra of 4-c showed no arylmethyl unit, and a new ${ }^{1} \mathrm{H}$ NMR peak appeared at about $5.7-6.0 \mathrm{ppm}$ which was identified as an NH unit. When polymer 3 film was reduced to less than $-3 \mathrm{~V}$, formation of an $\mathrm{NH}$ unit was observed. When the reduction potential was $-2.8 \mathrm{~V}$, formation of an $\mathrm{NH}$ unit was not observed. The standard redox potential for $\mathrm{Na} / \mathrm{Na}^{+}$(about $-3.1 \mathrm{~V}$ vs. $\mathrm{Ag} / \mathrm{Ag}^{+}$in acetonitrile $^{7}$ ) is almost the same as that of electrochemical formation of an $\mathrm{NH}$ unit, indicating that chemical reduction of $\mathbf{3}$ is energetically productive. Polymer with long alkyl chain (4c-c) was soluble in usual organic solvent. Solubility of 4-c was lower than that of related $\mathbf{3}$ because large substituent was removed. GPC data suggest that no significant decomposition of polymer backbone occurs by this reaction. This indicates that further reduction by sodium does not occur after the formation of 4 from 3. This agrees with CV of PPhenaz-Me not showing reduction current by electrochemical reduction. Reported poly(diphenylamine $)^{6 \mathrm{~b}}$ had high conductivity and solution of the polymer had high quantum yield. But the polymer was soluble only in trifluoroacetic acid and NMP. However, polymer 4-c was a soluble poly(diphenylamine) derivative.

Reaction of 3 and $\mathrm{H}_{2}$ with $\mathrm{Pd} / \mathrm{C}$ catalyst, a method for preparating $\mathrm{N}-\mathrm{H}$ type phenazasiline derivatives, ${ }^{8}$ did not give 4.

From Table I and Table II, UV $\lambda_{\max }$ of 4-c was longer

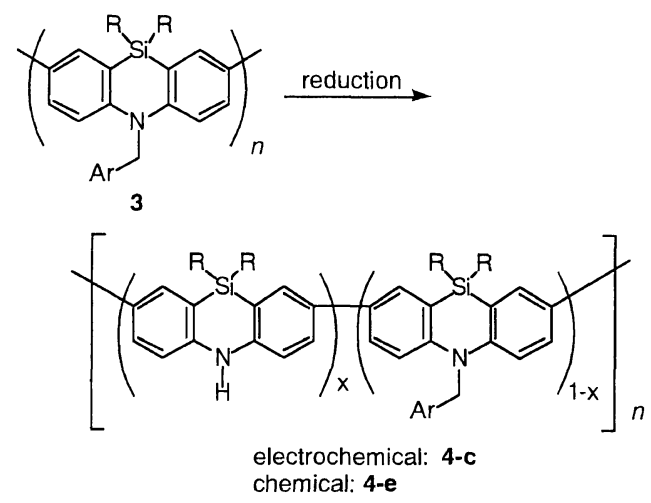

Scheme 2.

Table II. Results of preparation and spectral data of 4-c

\begin{tabular}{|c|c|c|c|c|c|c|}
\hline $\begin{array}{l}\text { Obtained } \\
\text { Polymer }\end{array}$ & $\begin{array}{l}\text { Starting } \\
\text { Polymer }\end{array}$ & $\mathrm{R}$ & Yield/\% & $M_{\mathrm{w}} / 10^{4 \mathrm{a}}$ & ${ }^{29} \mathrm{Si} \mathrm{NMR} / \delta^{\mathrm{b}}$ & $\mathrm{UV} \lambda_{\max } / \mathrm{nm}^{\mathrm{c}}$ \\
\hline $4 a-c$ & $\mathbf{3 a}$ & $\mathrm{Me}$ & 84 & $0.8(1.8)$ & -22.55 & 371 \\
\hline $4 b-c$ & $\mathbf{3 b}$ & $n-\mathrm{Bu}$ & 99 & $3.2(1.8)$ & -20.38 & 382 \\
\hline $4 c-c$ & 3c & $n$-Oct & 99 & $1.9(2.8)$ & -20.51 & 382 \\
\hline
\end{tabular}

${ }^{\mathrm{a}} \mathrm{GPC}$ (THF, polystyrene standard). Figure in parenthesis is $M_{\mathrm{w}} / M_{\mathrm{n}} .{ }^{\mathrm{b}} \mathrm{In} \mathrm{CDCl}_{3} .{ }^{\mathrm{c}} \mathrm{CHCl}_{3}$ solution. 
than that of $\mathbf{3}$ with the same substituent on the Si atom. CV of 4-c showed the same behavior as that of 4-e, which had lower oxidation potential that of 3. From these results, substituent on the $\mathrm{N}$ atom is essential for electrochemical and optical properties of poly(phenazasiline).

Acknowledgment. This work was supported by the New Energy and Industrial Technology Development Organization.

\section{REFERENCES}

1. a) Y. Ito, Jpn. Kokai, JP 08302339 (1996); Chem. Abstr., 126, 97071e (1997). b) V. O. Reisfel'd, Yu. S. Finogenov, S. S. Al'tman, L. B. Malikina, and N. I. Rozova, Issled. Obl. Fiz. Khim. Kauch. Rezin, 2, 14 (1973); Chem. Abstr. 83, 194811x (1975). c) C. Tamborski, Ann. N. Y. Acad. Sci., 125, 242 (1965).

2. a) H. Kondo, M. Sato, and M. Yokoyama, J. Polym. Sci., Polym. Chem. Ed., 21, 165 (1983). b) M. Mastragostino, A.
Zanelli, G. Casalbore-Miceli, and A. Geri, Synth. Met., 68, 157 (1995).

3. a) H. Hayashi, H. Nakao, A. Adachi, H. Kimura, K. Okita, T. Hayashi, and M. Tanaka, Chem. Lett., 688 (2000). b) H. Nakao, H. Hayashi, and K. Okita, Bunseki Kagaku, 49, 169 (2000).

4. H. Hayashi, S-y. Onozawa, H. Nakao, A. Adachi, K. Okita, T. Hayashi, and M. Tanaka, The 76th Annual Meeting of the Chemical Society of Japan, Yokohama, March, 1999, Abstr. No. 1C529.

5. D. Wasserman, R. E. Jones, S. A. Robinson, and J. D. Garber, J. Org. Chem., 30, 3248 (1965).

6. a) T. Yamamoto, in "Handbook of Organic Conductive Molecules and Polymers," H. S. Nalwa, Ed., John Wiley and Sons Ltd., New York, N.Y., 1997, vol. 2, chapt. 5, p 171. b) S.-B. Kim, K. Harada, and T. Yamamoto, Macromolecules, 31, 988 (1998).

7. "Kagaku Binran," 3rd ed, The Chemical Society of Japan, Ed., Maruzen, Co., Ltd., Tokyo, 1989, p II-477.

8. M. Urabe, A. Itoh, and K. Tanaka, The 76th Annual Meeting of the Chemical Society of Japan, Yokohama, March, 1999 Abstr. No. 3PA 142. 